\title{
Stage II Ureter Cancer AJCC v8
}

National Cancer Institute

\section{Source}

National Cancer Institute. Stage II Ureter Cancer A/CC v8. NCI Thesaurus. Code C140369.

Stage II includes: T2, NO, MO. T2: Tumor invades the muscularis. N0: No regional lymph node metastasis. M0: No distant metastasis. (AJCC 8th ed.) 